\title{
PRAKTIK UPETI DALAM TRADISI HEGEMONI NUSANTARA (Tela'ah kritis terhadap praktik mengakar KKN di Indonesia)
}

\author{
Yusuf Adam Hilman \\ Universitas Muhammadiyah Ponorogo \\ Email: adamhilman@umpo.ac.id
}

\begin{abstract}
Abstrak
Kajian ini bertujuan untuk mengetahui proses terjadinya praktik hegemoni yang menyebabkan tidak sadarnya masyarakat dalam melaksanakan praktik - praktik Upeti yang akhirnya memperkuat praktik KKN. Metode penelitian yang digunakan adalah deskriptif kualitatif dengan pendekatan sosiologis historis, yang mencoba melihat prilaku masyarakat secara teratur berdasarkan pembabakan waktu. Tradisi upeti yang telah di temukan dalam beberapa pembabakan waktu, memberikan pola terhadap beberapa konsep, yakni kekuasaan dalam perspektif jawa, yakni: “manunggaling kaula gusti”, konsep ini menempatkan bentuk penghormatan terhadap raja atau kalangan bangsawan dalam posisi tinggi dan juga sangat di hormati, sehingga berkembang kepercayaan bahwa kalangan priyayi atau bangsawan bisa membawa rakyat jelata menuju surga dan kemakmuran di dunia, praktik upeti dalam kondisi saat itu, masih berada dalam pengaruh kebudayaan hindu - budha yang sangat kuat dalam tradisi sistem kelas sosial, sehingga pemerintah kolonial belanda, yang mencoba menekan masyarakat nusantara dengan cara kekerasan dan budaya, supaya struktur kelas tetap terjaga, sehingga kepentingan pemerintah kolonial, yakni: "Glory, Gold, dan Gospel", dapat tetap terlaksana. Padahal dalam ajaran agama hindu tidak mengenal sistem kasta varnas melainkan model caturvanas yang lebih menekankan pada peranan, bukan pembagian kelas. Hal ini yang kemudian tereduksi dalam penyelenggaraan pemerintah di nusantara sebagai wujud budaya yang diyakini kebenaranyya, hingga dalam praktik kehidupan masyarakat pemberian upeti, sogokan, uang pelicin, gratifikasi, menjadi salah tafsir dan makna, hal ini yang membuat Indonesia mengalami kondisi darurat KKN.
\end{abstract}

Kata Kunci: Upeti, Hegemoni, Nusantara, KKN

\begin{abstract}
This study seeks to know the correct process the occurrence of the hegemony of practices, that causes unconsciousness the community in carrying out practices, the tribute which finally strengthen $(K K N)$ practices. The methodology used is qualitative descriptive the historical sociological, who tried to see the civil society regularly based on pembabakan time. Tradition tribute that has been found in some pembabakan time, give a pattern of several concept, namely power in perspective java, namely: "manunggaling kaula gusti", Tradition tribute that has been found in some pembabakan time, give a pattern of several concept, namely power in perspective java, namely. The tribute in conditions at the time, was still in the grip of Hindu - Budhis Culture ion system social class, so the Dutch colonial government. Who to score the community nusantara by violent means and culture, that structure the class stayed awake, so that the interests of the government colonial, for his, "Glory, Gold, dan Gospel", Can carry on. But in the training hinduism did not know a kasta system varnas but a model caturvanas more emphasis on the role, not classes This is then irreducible in the government in nusantara as a culture believed to be kebenaranyya, until in practice society the tribute, sogokan, uang pelicin, gratifikasi gratification, being misinterpretation and meaning, this is what makes indonesia experienced emergencies corruption.
\end{abstract}

Keyword: Upeti, Hegemoni, Nusantara, KKN.

\section{PENDAHULUAN}

Praktik Korupsi, Kolusi, dan

Nepotisme (KKN), dianggap sebagai

sebuah persoalan bangsa yang sifatnya darurat dan khusus, sehingga disebut sebagai extra ordinary crime atau tindak pindana bersifat luar biasa, yang memiliki model, pola, serta bentuk yang 
khusus. Terminologi KKN bisa menjadi sebuah pengetahuan awal tentang bagaimana istilah tersebut berkembang sehingga menghasilkan nama atau sebutan, supaya bisa cepat dikenali oleh masyarakat.

Indonesia menganggap Kejahatan KKN sebagai kejahatan luar biasa extra ordinary crime yang terjadi atau dilakukan secara khusus, sehingga perlu dilakukan penegakan hukum secara juga menggunakan cara - cara khusus. (Hadiati E, 2013)

Nyoman Serikat mengungkapkan bahwa: Tiga serangkai, Korupsi, Kolusi dan Nepotisme yang semula merupakan istilah umum, "public term" atau mungkin istilah ilmiah atau akademis, "scientific term", kemudian berkembang menjadi istilah yuridis “legal term”. Istilah korupsi menjadi istilah yuridis melalui Peraturan Penguasa Militer No. Prt/PM/06/1957 tentang Pemberantasan Korupsi, dan istilah Kolusi dan Nepotisme menjadi istilah yuridis melalui UU No. 28 tahun 1999 jo. Tap MPR No.XI/MPR/1998. Tiga serangkai Korupsi, Kolusi dan Nepotisme merupakan sumber malapetaka suatu rezim, seperti diungkapkan oleh Wakil Presiden Amerika Serikat, Al Gore. (Hadisuprapto, 2000)

Pemahaman awal terhadap praktik korupsi, kolusi, dan nepotisme, menurut kami masih kurang cukup, mengingat fenomena ini berdampak luar biasa terhadap tatanan Negara dan masyarakat, konsep KKN sendiri dapat dilihat dari berbagai sudut pandang atau persepektif, hal ini bertujuan untuk memberikan pemahaman dan juga kesadaran agar tidak melakukan tindakan - tindakan tersebut, melalui identifikasi pola - pola, ataupun bentuk nya.

Secara historis korupsi politik dapat meruntuhkan negara yang pal- ing perkasa sekalipun. Sejak raja Babilonia Hammurabi pasca tahun 1600an Sebelum Masehi sebagai pembuat Undang-undang tertulis pertama di dunia telah memuat larangan praktek suap. Seperti Edward Gibbon dalam bukunya yang monumental The History of the Decline and Fall of the Roman Empire yang memaparkan keruntuhan imperium kerajaan Romawi karena merajalelanya praktek korupsi. Demikian juga Alessandro Barbero, dalam bukunya: The Day of The Barbarians, The battle that Led To The Fall of The Roman Empire, antara lain memaparkan: “Corruption was endemic in the Roman Empire, and the entire system of contracts and supplies for the army had always offered unlimited opportunities for criminal gain". (Alkostar, 2008)

Di Indonesia sendiri secara historis, korupsi telah terjadi sejak zaman VOC, pada awal kemerdekaan, masa Orde Lama, Orde Baru, Masa 
Reformasi hingga saat ini. Telah banyak perangkat hukum dan perundangundangan diberlakukan, tetapi intensitas dan kualitas kejahatan korupsi tetap meningkat. Cita-cita kemerdekaan dan tujuan reformasi dihadang oleh deretan koruptor baik yang berada dalam kekuasaan negara yang culas maupun pengusaha yang rakus. Untuk itu perlu diperbanyak dan dirapatkan barisan anti korupsi agar tiang Negara menjadi tegak dan bermartabat. (Alkostar, 2008)

Upaya memberikan pemahaman dan juga kesadaran terhadap masyarakat harus dilakukan dengan optimal, tidak hanya memberikan pemahaman terhadap dampaknya saja, melainkan terhadap karakteristik, pola pola, serta bentuk - bentuk yang muncul dari praktik tersebut. pemberian pemahaman tersebut bisa dilakukan dengan pendekatan historis, dimana praktik tersebut diidentifikasi melalui pembabakan waktu, secara konsisten untuk menentukan kesamaan ataupun pola - pola khusus yang terbentuk.

Berangkat dari konsep upeti yang sudah berlangsung lama, sejak era kerajaan - kerajaan Nusantara, disinilah ada indikasi bahwa praktik korupsi, kolusi dan nepotisme (KKN) tumbuh subur melalui dimensi budaya yang terkait dengan konsep kekuasaan, kemudian tereduksi dalam kehidupan masyarakat, tidak hanya itu saja, tradisi tersebut dilanggengkan melalui hegemoni pemerintah kolonial yang memiliki misi terselubung di Nusantara.

Secara historis, di suatu sistem pemerintahan yang menggunakan sistem monarkhi, maka tradisi korupsi sangat kelihatan. $\mathrm{Di}$ dalam sistem pemerintahan monarkhi Jawa, maka dikenal konsep pemberian untuk memperoleh perlindungan, baik perlindungan keselamatan maupun jabatan. Agar status dan kedudukan seseorang selamat, maka imbalan yang diberikan adalah dengan memberikan upeti yang di dalam tradisi Jawa disebut gelondong pengarem-arem. Yaitu sebuah pemberian dari seorang pejabat yang lebih rendah kepada yang lebih tinggi sebagai bentuk pemberian kesenangan, pengarem-arem. Biasanya pemberian itu berbentuk emas picis rojobrono atau emas permata dan harta kekayaan. Upeti sebagai kewajiban pemberian dari pejabat tersebut biasanya, dari seorang bupati atau adipati kepada raja, atau dari seorang wedono kepada bupati. Ada semacam tradisi bertahap dalam pemberian dimaksud. Bahkan ada banyak tindakan yang dianggap sebagai pembangkangan jika seorang bupati tidak memberikan upeti kepada rajanya. (Syam, 2007)

Praktik korupsi saat ini pada hakikatnya tidak terputus dengan apa yang terjadi di masa lalu. Warisan 
feodalisme dengan praktik upetinya menjadi cikal bakal dari budaya korupsi. Namun bukan berarti lantas kita hanya dapat memakluminya dan menganggapnya sebagai sebuah kewajaran budaya. Tradisi upeti pada masa lalu bisa jadi adalah biang kerok praktik korupsi pada masa kini. Pranoto menggambarkan masyarakat Indonesia sebagai orang yang lama sakit (selama masa penjajahan) dan ketika sembuh (pasca kemerdekaan) mendamba semua jenis makanan sebagai kompensasi. Sekarang ini kita berada dalam "fase kemaruk" ditandai dengan perilaku koruptif dan konsumtif. (Setyowati, 2012)

Praktik KKN yang berakar pada budaya pemberian upeti, sangat menarik karena dari sinilah konsep tersebut akan di identifikasi, guna menemukan pola, dan juga karakteristik yang bisa menjelaskan tentang perkembangan upeti hingga bertransformasi menjadi praktik KKN. Permasalahan dalam kajian ini adalah keterkaitan tentang bagaimana fenomena upeti terbentuk dan bertransformasi menjadi praktik korupsi, kolusi dan nepotisme.

Penelitian ini nantinya diharapkan dapat memberikan gambaran, pemahaman, serta dapat mempengaruhi masyarakat tentang fenomena tradisi pemberian upeti yang banyak menimbulkan efek negatif bagi kehidupan masyarakat, sehingga perlu ditinggalkan, dan di rubah supaya bisa merubah tradisi lama yang merusak Negara Indonesia yaitu praktik KKN.

\section{METODE PENELITIAN}

Penelitian ini mengunakan metode kualitatif deskriptif, untuk mengungkap fenomena yang terkait dengan keberadaan upeti dalam kehidupan masyarakat Indonesia. atau dengan kata lain penelitian ini mengungkap apa yang ada di balik prilaku masyarakat terkait realitas yang ada.

Penelitian kualitatif disebut studi kasus, karena objek yang diteliti bersifat unik, kasuistis, tidak ada duanya. Penelitian kualitatif disebut etnografi, etnometodologi, fenomenologi karena mengkaji perilaku manusia, kebudayaan, dan interaksi antarmanusia. (Atmadja, 2013)

Pendekatan fenomenologik / pascapostivistik berakar pada tradisi dalam sosiologi dan antropologi yang bertujuan untuk memahami suatu gejala seperti apa adanya tanpa harus mengontrol variabel dan tidak berusaha menggeneralisasi gejala tersebut dalam gejala-gejala yang lain. Termasuk dalam penel itian ini adalah etnografi, studi kasus, studi naturalistic, sejarah, biografi, teori membumi (grounded theory), dan studi deskriptif. (Mulyadi, 2011) 
Pengumpulan data melalui studi dokumentasi dilakukan untuk memperoleh data yang sudah tersedia pada berbagai instansi seperti data data tentang monografi desa serta arsip yang berkaitan dengan permasalahan penelitian. Analisis data dilakukan dengan cara menyusun data yang telah diperoleh berdasarkan atas golongan golongan dalam pola - pola, tema tema, atau kategori - kategori. Selanjutnya diadakan interpretasi yakni dengan cara memberikan makna, menjelaskan pola atau kategori dan juga mencari keterkaitan antara berbagai konsep.

Dengan cara itu diharapkan gejala gejala yang dibahas dalam penelitian yang bersifat kompleks akan dapat dideskripsikan dan dijelaskan dalam kualitas yang mendekati kenyataan. (Haryono, 2005)

Sesuai pengalaman penulis, aspek validitas dan reliabilitas dapat menjelaskan berbagai teknik operasional yang mendukung rigoritas (ketepatan) data yang dihasilkan dalam penelitian kualitatif, yaitu: 1). kredibilitas, Kredibilitas menjadi suatu hal yang penting ketika mempertanyakan kualitas hasil suatu penelitian kualitatif. Standar kredibilitas ini identik dengan standar validitas internal dalam penelitian kuantitatif. Suatu hasil penelitian kualitatif dikatakan memiliki tingkat kredibilitas yang tinggi terletak pada keberhasilan studi tersebut mencapai tujuannya mengeksplorasi masalah atau mendeskripsikan setting, proses, kelompok sosial atau pola interaksi yang majemuk/kompleks. 2). dependabilitas, Istilah reliabilitas dalam penelitian kualitatif dikenal dengan istilah dependabilitas. Konsep reliabilitas ini juga sering manjadi pertimbangan lain dalam menilai keilmiahan suatu temuan penelitian kualitatif. Pertanyaan mendasar berkaitan dengan isu reliabilitas adalah sejauh mana temuan penelitian kualitatif memperlihatkan konsistensi hasil temuan ketika dilakukan oleh peneliti yang berbeda dengan waktu yang berbeda, tetapi dilakukan dengan metodologi dan interview script yang sama. 3). konfirmabilitas,

Objektivitas/konfimabilitas dalam penelitian kualitatif lebih diartikan sebagai konsep intersubjektivitas atau konsep tranparansi, yaitu kesediaan peneliti mengungkapkan secara terbuka tentang proses dan elemen-elemen penelitiannya sehingga memungkinkan pihak lain/peneliti lain melakukan penilaian tentang hasil-hasil temuannya. dan 3). transferabilitas. Transferabilitas merupakan istilah yang dapat menggantikan konsep generalisasi data dalam penelitian kuantitatif, yaitu sejauh mana temuan suatu penelitian yang dilakukan pada suatu kelompok 
tertentu dapat diaplikasikan pada kelompok lain. (Afiyanti, 2008)

\section{HASIL DAN PEMBAHASAN}

\section{Pembabakan Waktu (Periodesasi}

Sejarah)

Perjalanan bangsa yang panjang, membawa kita pada kondisi dimana Indonesia pada proses pembentukan hingga kini, memiliki rentetan pristiwa sejarah yang panjang dan lama, hal ini bertujuan untuk menentukan pembabakan waktu supaya mempermudah dalam hal pembahasan analisa data. Ada beberapa kesepakatan yang di buat oleh para sejarawan yang melakukan pembabakan waktu dalam sejarah bangsa.

Penyusunan periode sejarah yang mutakhir ini apabila diperhatikan merupakan kelanjutan dan penyempurnaan dari periodisasi yang telah berlaku pada penulisan sejarah nasional Indonesia sebelumnya 1970. Periodesasi tersebut menjadi sebuah periodisasi mutakhir yang dicapai pada masa kini, sebagaimana tercermin dalam penerbitan buku sejarah Indonesia sebanyak 8 jilid, yang diharapkan selesai diterbitkan pada athun 2008 ini. Kedelapan jilid tersebut tampak disusun secara kronologis untuk mewakili masing - masing periode perkembangan sejarah Indonesia dari masa prasejarah hingga masa Mutakhir, seperti yang tergambar berikut ini. 1).
Masa Prasejarah (jilid I), 2). Masa Hindu Budha (jilid II), 3). Masa Islam (jilid III), 4). Masa Penjajahan dan Perlawanan (jilid IV), 5). Masa Gerakan Kebangsaan (jilid V), 6). Masa Perang dan Revolusi (jilid VI), 7). Masa Pasca Revolusi (jilid VII), 8). Masa Reformasi dan Akibatnya (jilid VIII). (Suryo, 2009)

Menurut Gazalba Dalam penyusunan babakan masa (periodesasi) dapat dipakai dasar sudut pandangan yang bermacam-macam, selain yang telah diajukan oleh pemasaran, yakni: a. memakai dasar perkembangan peradaban (civilizations), b. babakan masa didasarkan segi-segi kebudayaan (culture), c. babakan masa atas dasar agama-agama yang masuk di Indonesia; d. pembabakan seluruh sejarah nasional dalam lima babakan; 1. prasejarah, 2. proto sejarah, 3.babakan kebangsaan, 4. Babakan pertemuan antara bangsa Indonesia di tanah Indonesia, 5.Babakan abad proklamasi berdasarkan adanya pembentukan masyarakat Indonesia yang berdaulat - dengan pengertian, bahwa Negara yang kekuasaanya meliputi seluruh Indonesia, dan Negaranegara yang kurang luasnya daripada kekuasaanya itu, adalah suatu susunan masyarakat. (Hilman, 2017)

\section{Era Pra sejarah}

Arca Megalitik merupakan peninggalan pada masa megalitik yang juga merupakan salah satu hasil karya 
seni asli nenek moyang bangsa Indonesia. Arca Megalitik adalah sebuah patung yang dibuat dari batu yang memiliki bentuk pahatan atau ukiran yang sangat sederhana. Arca Megalitik juga merupakan karya seni yang bersifat sakral atau religius-magis. Pembuatan bangunan megalitik pada umumnya berpangkal pada suatu konsepsi yang berasal dari kepercayaan dan pemujaan terhadap roh nenek moyang. Termasuk dalam pembuatan Arca Megalitik yang dibuat untuk dijadikan sebagai media pemujaan kepada roh-roh nenek moyang. (Gunawan, 2014)

Seperti masyarakat tradisional lainnya di Indonesia, masyarakat Gayo pada masa lalu juga menggunakan roh tertentu untuk berbagai kepentingan sosial, roh orang yang meninggal, atau tokoh tertentu dengan memberikan persembahan agar segala keinginannya terpenuhi. (Wiradnyana, 2015)

Ciri lain masyarakat Indonesia lama adalah kuatnya ikatan solidaritas sosial dan hubungan pertalian darah. Dalam masyarakat Jawa, pendewaan dan pemitosan terhadap ruh nenekmoyang melahirkan penyembahan ruh nenek-moyang "ancestor worship" yang pada akhimya melahirkan hukum adat dan relasi-relasi pendukungnya. Dengan upacara-upacara selametan, ruh nenek moyang menjadi sebentuk dewa pelindung bagi keluarga yang masih hidup. (Chakim, 2008)
Era Sejarah (Kerajaan Hindu, Budha, serta Islam)

Dalam kerajaan tradisional, agama dijadikan sebagai bentuk legitimasi. Pada zaman Hindu-Budha diperkenalkan konsep dewa-raja atau raja titising dewa. Hal ini berarti bahwa rakyat harus tunduk pada kedudukan raja untuk mencapai keselamatan duniaakhirat, Agama diintegrasikan ke dalam kepentingan kerajaan/kekuasaan. Kebudayaan berkisar pada raja, tahta, dan keraton. Raja dan kehidupan keraton adalah puncak peradaban pada masa itu. (Chakim, 2008)

Statecraft adalah sebuah istilah untuk sebuah kerajaan pertanian yang khas yang dilengkapi oleh struktur filosofis budaya agraris, kosmis, mistis, dan simbolis. Kondisi ini menciptakan suatu konsep budaya politik dan kenegaraan yang mengakumulasikan sistem perubahan sosial budaya yang radikal. Pada mulanya mataram di bawah kekuasaan sultan Agung (16131645) merupakan peletak dasar konsep ketatanegaraan dan sistem politik yang mensinkretiskan atau bahkan mengkompromikan sistem formal dengan supranatural, yang merupakan upaya pemahaman atas perubahan sosial budaya yang terjadi pada masa itu. Kompromi yang dilakukan atas perubahan dari suatu peradaban Hindu Budha (disebut zaman kebudan) kearah 
pengaruh Islam (disebut zaman Kewalen). Untuk itulah Kesultanan Mataram yang sejak zaman Pra Islam telah menerapkan sistem kekuasaan berdasar konsep God - King atau raja itu penjelmaan dewa (seperti halnya di beberapa Negara Asia Selatan, Timur dan Asia Tenggara), maka ketika Islam telah menjadi Agama Negara dan Rakyat, konsep ini tetap dilakukan dengan mengganti nama meskipun subtansinya sama. Istilah baru untuk hal ini adalah Dewa diganti dengan ungkapan simbolik union mistik manunggaling kawula gusti. Hal ini masih bersifat statecraft yang merujuk pada konsep politik religius. Konsep Raja sebagai wakil Tuhan di Bumi di pertahankan di Jaw menjadi Sumber (Core) sebuah sistem kekuasaan. (Wurianto, 2001)

\section{Era Kolonialisasi (Belanda dan Jepang)}

Sementara itu arus kolonialisasi mulai merebak ke seantero dunia, kaetika di Eropa mengalami krisis finansial, beberapa ahli diutus oleh para saudagar dan kerajaan di Eropa untuk mencari sumber - sumber alam baru di luar daratan Biru, Islam yang dating lebih dahulu yang mulai banyak merubah kehidupan masyarakat Nusantara, kemudian memasuki era di mata para pedagang dan Ilmuan mulai mendarat di berbagai pulau di pesisir
Nusantara, alhasil mereka setelah kembali ke negaranya menarik beberapa ekspansi besar - besaran bangsa Eropa ke Nusnatara, disinilah kemudian dimulai kolonialisasi, yang diawali oleh bangsa Portugis, kemudian dilanjutkan oleh bangsa - bangsa Belanda dan Inggris. Tidak hanya sampai distu, bangsa Asia timur juga mulai melakukan ekspansi setelah sekian lama nusantara dikuasai oleh kerjaaan Hindia Belanda, diantaranya kekaisaran Jepang, yang membutuhkan sumber kekayaan baru untuk membiayai perang yang sedang dilakukan di dunia. (Hilman, 2017)

Masa kolonialisasi merupakan masa - masa paling berat bangsa ini, masa masa perjuangan di daerah yang sangat menguras tenaga dan juga pikiran, di era ini juga kemudian muncula tokoh tokoh nasional yang berjuang untuk melepaskan diri dari cengkraman penjajahan. Perjuangan memperoleh kemerdekaan kemuadian telah tercapai, disinilah kemudian bangsa Indonesia terbentuk dan menyempurnakan bentuk dan dasar Negara, di era ini pergolakan juga terjadi ketika berbagai elit mulai melakukan perang ideology guna menancapkan pengaruhnya masing masing. Berbagai pemberontakan juga terjadi ideology, nasionalis, komunis dan agamis berkompetisi untuk menjadi pemenang, berbagai pristiwa pun terjadi Pemberontakan Permesta, G30S - PKI, dan berbagai kudeta coba 
dilakukan dan pristiwa historis mulai bergulir dan silih berganti. Era kemerdekaan kemudian beralih ke zaman dimana kalangan Nasionalis mulai menguasai, di era ini lebih dikenal dengan masa pemerintahan orde baru dan orde lama dibawah pimpinan Jendras Soeharto yang melakukan gerakan Pancasila, dengan karakteristik kepemimpinan Militer yang menjadi cirri khasnya. (Hilman, 2017)

Sistem birokrasi pemerintahan yang dikembangkan pemerintah colonial justru sepenuhnya ditujukan untuk mendukung semakin berkembangnya pola paternalistik yang telah menjiwai sistem birokrasi pada era kerajaan. Meskipun terjadi pembaharuan sistem birokrasi pada masa pemerintahan kolonial, secara substansial sebenarnya tidak mengubah corak birokrasi pemerintah dalam berhubungan dengan publik. Sentralisasi kekuasaan dalam birokrasi masih tetap sangat dominan dalam praktik penyelenggaraan kegiatan pemeritnahan. Pembuatan berbagai keputusan dan kebijakan publik oleh birokrasi pemerintah tidak pernah bergeser dari penggunaan pola topdown. Substansi dari persoalan korupsi dalam birokrasi pada dasarnya merupakan bagian dari feodallisme yang terus dipelihara oleh sistem birokrasi. (Hasan, 2012)

\section{Era Kemerdekaan, reformasi dan saat Ini}

Seiring dengan perjalanan sejarah, pemerintahan Soeharto memimpin Indonesia selama 32 Tahun dimasa itu, pemerintahan dijalankan secara sentralistik dan militerisme, kondisi tersebut pada ujung ekepemimpinannya memabawa pada kondisi perekonomian yang sulit, kemudian berbaga lini atau elemen masyarakat sudah mulai muak dan juga tidak lagi percaya sehingga terjadi aksi besar - besaran pada tahun 1998 untuk menggulingkan pemerintahan yang berkuasa, kemudian setelah lengsernya Presiden Soeharto akhirnya bangsa ini memasuki era reformasi, dimana terjadi perombakan besar - besaran dalam sistem pemerintahan Indonesia, namun kondisi tersebut masih tidak stabil, hingga terjadi pemilihan presiden hingga berkali - kali, belum juga merasakan efek kesejahteraan. Fenomena korupsi, kolusi dan nepotisme dirasakan malah semakin tidak terkontrol, alhasil banayak kepala daerah dan pejabat tinggi yang terkena kasus, hingga birokrasi dan aparatur pemerintah menjadi sorotan yang paling utama, ketika kondisi Negara terpuruk karena praktik - praktik KKN. (Hilman, 2017)

Kondisi tersebut kemudian dapat dijelaskan bahwa pola, karakteristik di setiap periodesasi di temukan, semuanya bermuara pada konsep 
kekuasaan atau otoritas yang dimiliki atau yang terbentuk baik formal maupun non formal, sehingga tradisi pemberian yang kemudian berubah menjadi, upeti telah berkembang dan mengalami perubahan dalam kehidupan masayarakat, secara sadar atau tidak.

Tabel 1. Contoh Pelembagaan Praktik Upeti, Suap, dan Gratifikasi

\begin{tabular}{l|l}
\multicolumn{1}{c|}{ Periodesasi } & \multicolumn{1}{c}{ Upeti, Suap, Gratifikasi } \\
\hline Zaman Pra sejarah & $\begin{array}{l}\text { Bentuk Persembahan kepada roh leluhur dengan konsep } \\
\text { animism dan dinamisme }\end{array}$ \\
\hline Zaman Sejarah & $\begin{array}{l}\text { Era kerajaan dengan periode hindu, budha serta Islam yang } \\
\text { memperkuat tradisi statescraft dengan model kekuasaan } \\
\text { religius (manunggaling kawula gusti). }\end{array}$ \\
\hline Zaman Kolonial & Melahirkan tradisi Paternalistik \\
\hline Zaman Kemerdekaan & Mereduksi sistem birokrasi tradisional \\
\hline Zaman Pasca Reformasi & $\begin{array}{l}\text { Uang sogokan, suap dan lain - lain terhadap penguasa atau } \\
\text { orang - ornag yang memiliki kewenangan }\end{array}$ \\
\hline Zaman Sekarang & Berubah menjadi suap dan gratifikasi.
\end{tabular}

Sumber: diolah dari data yang berhasil di himpun.

Periode sejarah memberikan gambaran bahwa upeti kemudian tereduksi dalam ruang - ruang kekuasaan dan kewenangan, baik secara resmi maupun tidak, terlebih adanya hegemoni yang dilakukan oleh para penguasa melalui tindakan yang menggunakan kekerasan serta cara cara halus, akhirnya memaksa kelas sosial yang ada tetap menjalankan tradisi upeti yang dibawa dari kebudayaan era hindu - budha yang ada di pulau jawa, dengan corak yang begitu patron, sehingga upeti bertransformasi kedalam beberapa bentuk, mengikuti perkembangan zaman.
Praktik - praktik pelembagaan pemberian Upeti, Suap, dan Gratifikasi, tereduksi dalam konsep kekuasaan, dimana kekuasaan yang ada, melalui Negara atau pemilik otoritas coba melakukan hegemoni, secara sadar atau tidak kepada masyarakat, agar secara terus menerus melakukan praktik praktik tersebut bisa dilanggengkan oleh kelompok elit, sehingga upeti kemudian berubah menjadi berbagai praktik menguntungkan diri sendiri, melalui kekuasaan yang dimiliki.

\section{KESIMPULAN \\ Perjalan sejarah telah menjelakan bahwa praktik upeti yang}


telah dilakukan selama ini, ternyata berpengaruh besar terhadap praktik Korupsi, Kolusi dan Nepotisme (KKN), yang saat ini di alami bangsa kita, bahkan kondisinya sangat memprihatinkan, kondisi tersebut harus disikapi dengan pemahaman yang baik, sejarah telah membuka tabir upeti, yang sekali lagi berhasil dijadikan senjata oleh pemerintah penjajah melalui konsep hegemoni, untuk memporak - porandakan bangsa kita, sehingga penting bagi kita jika knowledge terkait "upeti" bisa menjadi pengetahuan yang bermanfaat dan bisa menjadi referensi dalam penyelesaikan praktik - praktik berdosa seperti KKN.

\section{UCAPAN TRIMAKASIH}

Trimakasih atas dukungan yang diberikan semua pihak, yang berkenan membantu dalam penyelesaian atikel ini, terutama bagi institusi kami, Fakultas Ilmu Sosial dan Ilmu Politik, Universitas Muhammadiyah Ponorogo.

\section{DAFTAR PUSTAKA}

Afiyanti, Y. (2008). Validitas Dan Reliabilitas Dalam Penelitian Kualitatif. Keperawatan Indonesia , 137 - 141.

Alkostar, A. (2008). Mengkritisi Fenomena Korupsi Di Parlemen. Hukum , 1-13.

Atmadja, A. T. (2013). Pergulatan Metodologi Dan Penelitian Kualitatif Dalam Ranah IImu Akuntansi. Akuntansi Profesi, $122-141$.

Chakim, S. (2008). Dakwah Clan Dialektika Budaya Jawa Dalam
Lintasan Sejarah. Komunika, 42 53.

Gunawan, I. W. (2014). Identifikasi Arca Megalitik Di Pura Ulun Suwi Desa Pakraman Selulung (Kajian Tentang Sejarah Dan Potensinya Sebagai Sumber Pembelajaran Ips Pada Smp Berdasarkan Kurikulum 2013). Widya Wiyanata , 6 - 11.

Hadiati E, I. A. (2013). Konstruksi Media Terhadap Pemberitaan Kasus Perempuan Koruptor. Al-Ulum , 345-372.

Hadisuprapto, P. (2000). Pemberian Malu: Alternatif Antisipatif Korupsi, Kolusi Dan Nepotisme (K.K.N). Kriminologi Indonesia , 1 - 9.

Haryono, T. J. (2005). Strategi Kelangsungan Hidup Nelayan Studi Tentang Diversifikasi Pekerjaan Keluarga Nelayan Sebagai Salah Satu Strategi Dalam Mempertahankan Kelangsungan Hidup. Berkala Ilmiah Kependudukan , 119 128.

Hasan, M. N. (2012). Corak Budaya Birokrasi Pada Masa Kerajaan, Kolonial Belanda Hingga Di Era Desentralisasi Dalam Pelayanan Publik. Hukum , 1073-1087.

Hilman, Y. A. (2017). Upeti Sebagai Bentuk Hegemoni. Ponorogo: Cv. Calina Media.

Mulyadi, M. (2011). Penelitian Kuantitatif Dan Kualitatif Serta Pemikiran Dasar Menggabungkannya. Jurnal Studi Komunikasi Dan Media , 127 138.

Setyowati, D. (2012). Dekonstruksi Korupsi Dalam Demokratisasi Indonesia. International Conference On Business, International Relations And Diplomacy-Icobird 2012, (Pp. 1 14). Yogyakarta.

Suryo, D. (2009). Periode Sejarah Indonesia : Dari Smenjak Seminar Sejarah Di Yogyakarta 1957 Hingga Masa Kini. Sejarah , 17 31. 
Syam, N. (2007). Indonesia Di Tengah Problem Keterpurukan: Memotong Tradisi Korupsi. Forum Seminar Di Universitas Bhayangkara Surabaya, (Pp. 1 8). Surabaya: Universitas Bhayangkara Surabaya, .

Wiradnyana, K. (2015). Perkembangan Religi Prasejarah: Tradisi Masyarakat Gayo. Amerta (Jurnal Penelitian Dan Pengembangan Arkeologi) , 1-12.

Wurianto, A. B. (2001). Gung Binatara : Kekuasaan dan Moralitas Jawa (Kasus Religiusitas Sultan Agung Di Mataram. Ilmiah Bestari , 46 52. 